\title{
The atmospheric circulation on the synoptic scale during the culmination phase of the El-Niño - Southern Oscillation events (1997-1998)
}

\author{
E. V. Sokolikhina ${ }^{1,2}$, E. K. Semenov ${ }^{2}$, and N. N. Sokolikhina ${ }^{2}$ \\ ${ }^{1}$ P. P. Shirshov Institute of Oceanology, Moscow, Russia \\ ${ }^{2}$ Meteorological Department, Moscow State University, Moscow, Russia
}

Received: 27 June 2005 - Revised: 9 November 2005 - Accepted: 14 November 2005 - Published: 9 January 2006

\begin{abstract}
For the classification of the synoptic processes in the tropical Pacific using daily data, criteria were proposed for identifying the different evolutional phases of the equatorial westerly wind zone. The criteria are based on the location, extent and activity of the westerly wind zone on the $850 \mathrm{hPa}$ isobaric surface. According to this classification all the observed variants of the westerly wind regime above the tropical Pacific can be divided into three classes: normal, active, and break. For each class one specific pattern of tropical atmospheric circulation centers and divergent wind velocity potential in the lower and upper troposphere are found.

Using the singular value decomposition method (SVD) the connection between the atmospheric circulation and sea surface temperature (SST) of equatorial Pacific is investigated.
\end{abstract}

\section{Introduction}

The subequatorial westerly winds are important components of the Global Atmospheric Circulation in low latitudes. They replace the classical easterly (trade) winds above the tropical Pacific and form the zonal circulation anomaly in the lower troposphere. The westerly winds culminate in the culmination phase of the ENSO events. Therefore there is a necessity to investigate the location and intensity of the equatorial westerly winds.

The analysis of the synoptic processes in low latitudes and the results of the spectral analysis of the wind fields and cloudiness show that the synoptic processes play the main role in the equatorial westerly wind regime above the tropical Pacific (Harrison and Vecchi, 1995; Hartten, 1995). It is difficult to explain the synoptic processes based on average meteorological characteristics. Therefore daily data are used to investigate the synoptic conditions during the period when equatorial westerly winds form in the warm phase culmination of ENSO. The 1997-1998 El-Niño event is used because this was the strongest one during the whole observing period.

\section{Data and method}

We focus our investigation on the region of the tropical zone above the Indian and Pacific Oceans (30 S-20 N, $100 \mathrm{E}-$ $80 \mathrm{~W}$ ) and use the NCEP/NCAR daily data (in grid $2.5 \times 2.5$ ) on real wind (zonal and meridional components) for December 1997-January, February 1998 on the isobaric surfaces 850,500 and $200 \mathrm{hPa}$. In addition to the maps of the zonal wind component and the divergent wind velocity potential, the resultant wind vector maps are plotted. The action centers of the tropical atmosphere are drawn using the current streamlets. Moreover the daily photos of the cloudiness from the Japanese geostationary satellite GSM are used for the investigated period.

To investigate the connections between atmospheric circulation and sea surface temperature (SST) of equatorial Pacific for synoptic scale processes during El-Niño (1997-1998) and La-Niña events (1999-2000) the singular value decomposition method (SVD) is used. For the description of the Pacific region 5 points (the averaged data over the ten-grid squares) are chosen, which describes most adequately the circulation fields in the equatorial Pacific (Fig. 1). The first point is situated in the region of Australian summer monsoon; the second and third one are located in the westerly wind zone. The fourth and fifth points are in the region of the southern trade winds near the coast of Peru and Ecuador. 


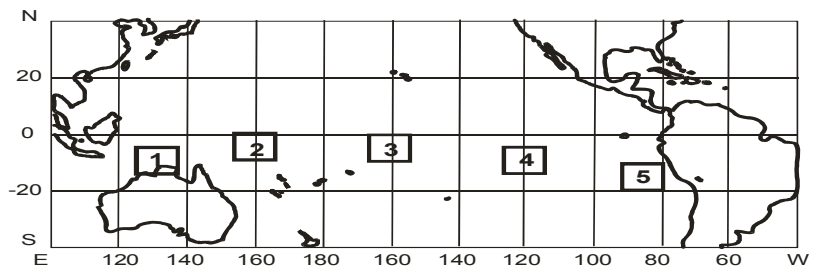

Fig. 1. The points for the description of the Pacific region which are used for the SVD-analysis.

\section{Analysis of the results}

Earlier, the Meteorological Department of the Moscow State University (Petrosyants et al., 1998) made a classification of the synoptic processes above the tropical Pacific for the relatively strong ENSO event of 1982-1983 using daily data. Criteria were proposed for identifying the different evolutional phases of the equatorial westerly wind zone during the culmination phase of ENSO events, associated with extreme Niño3. The criteria are based on the location, extent and activity of the westerly wind zone on the $850 \mathrm{hPa}$ surface. According to this classification all the observed variants of the westerly wind regime above the tropical Pacific can be divided into three classes: normal, active, and break. And for each class one specific pattern of tropical atmospheric circulation centers and divergent wind velocity potential in the lower and upper troposphere are found.

According to this classification, the normal class includes the cases when the equatorial westerly winds do not extend east of the date line and their velocities are within $5-9 \mathrm{~m} / \mathrm{s}$. In the classification of tropical cyclones such wind velocities characterize the tropical depression and the date line coincides in the climatic atlas (Semenov and Kornyushin, 1988) with a zero isotach of the westerly winds, east of which the easterly (trade) winds begin. The center of maximum velocities is naturally located not nearby the date line, but shifted to North Australia and New Guinea.

The active class includes the cases when the equatorial westerly winds extend in a continuous zone from the westerly regions of the tropical Pacific to the east up to 140$130 \mathrm{~W}$, i.e. $4000-5000 \mathrm{~km}$ east from their average climatological location and the wind velocities are within $10-20 \mathrm{~m} / \mathrm{s}$ (the wind velocities of the tropical storms).

The break class includes the cases when the equatorial westerly winds are fragment, i.e. the extent of single centers of westerly wind component does not exceed 10 degrees in longitude and the velocities are within 1-4 m/s.

During the ENSO culmination phase (three summer months of the Southern Hemisphere) the activity of equatorial westerly winds changes from 8 to 12 times, i.e. average every $8-10$ days there is a change in the regime of atmospheric circulation.

The analysis of the typical classes shows that the westerly wind anomaly above the tropical Pacific strongly depends on the conditions of tropical cyclogenesis, which is character-
Table 1. The proportion of the different westerly wind activity classes during the culmination ENSO phase (DJF).

\begin{tabular}{ccc}
\hline & \multicolumn{2}{c}{ El-Niño } \\
Class & $1982-1983$ days/\% & $1997-1998$ days/\% \\
\hline Normal & $35 / 39 \%$ & $10 / 11 \%$ \\
Active & $36 / 40 \%$ & $61 / 68 \%$ \\
Break & $19 / 21 \%$ & $19 / 21 \%$ \\
\hline
\end{tabular}

ized by large variability. Thus there are days when $8-9$ tropical cyclones of different intensity exist simultaneously above the tropical Pacific (the active class) and in some days of the ENSO culmination phase cyclonic vortices are not observed at all and the anticyclonic circulation is ill-defined (the break class).

To confirm the main results of the work (Petrosyants et al., 1998) it is interesting to estimate the conditions of the tropical cyclogenesis and, connected with it, the westerly winds during the ENSO 1997-1998. The maximum development of the ENSO 1997-1998 is also observed during the Southern Hemisphere summer (DJF).

The investigations show that, firstly, as with the ENSO $1982-1983$, in $21 \%$ of all cases (and this constitutes one fifth of the whole culmination period of the ENSO 1997-1998) the equatorial westerly wind zone above the tropical Pacific is very weak or does not exist at all (the break class) (Table 1). Such a result is rather unexpected, taking into account that the ENSO 1997-1998 is the strongest in the XX century.

Secondly, the active class during the ENSO 1997-1998 is observed twice as often than during the ENSO 1982-1983. Therefore we have an opportunity to subdivide all synoptical situations within the active class into three more typical variants of the location of equatorial westerly winds above the tropical Pacific.

The first variant of the active class is frequently observed when the equatorial westerly winds in the lower troposphere occupy virtually the entire easterly and central tropical $\mathrm{Pa}$ cific from Indonesia to $130 \mathrm{~W}$, and the westerly wind velocities above the central Pacific exceed 20-22 m/s. (Fig. 2a). Also it is shown that the westerly winds weaken in the system of summer Indian monsoon above Northern Australia. Virtually the entire northern monsoonal part of Australia is located in the easterly (trade) wind zone.

The second variant, observed three times less frequently than the first one, is characterized by the continuous equatorial westerly wind zone above the entire equatorial Pacific from Indonesia to the coasts of Colombia and Ecuador. At the same time the westerly wind velocities do not exceed 6- $8 \mathrm{~m} / \mathrm{s}$ above the central Pacific. The width of this zone changes from 1000 to $2000 \mathrm{~km}$ (close to the coast of Southern America) and its length is approximately $16000 \mathrm{~km}$, which is more than one third of the equatorial circle (Fig. 2b). In the central Pacific a weakening of the westerly wind velocities to $1-5 \mathrm{~m} / \mathrm{s}$ is observed. The westerly wind appearance 
above parts of the coast of Southern America, completely replacing the south-east trade winds, leads to heavy rain above this region.

The third variant, having the same recurrence as the second one, is characterized by the appearance of a vast equatorial westerly wind zone above the extreme easterly parts of the Pacific, including the littoral regions of Colombia, Ecuador and Peru. And at the same time the equatorial westerly winds exist also above the central and westerly parts of the Pacific, not connected with the westerly wind zone above the easterly Pacific (Fig. 2c). And the tropical cyclones appear both to the north $(5-10 \mathrm{~N})$ and to the south (10 S) of the equator. All these cause the appearance of equatorial westerly winds above this region, transferring the convectively unstable air masses from the anomalous warm water to the regions of the north-west coast of Southern America. And this fact leads to catastrophic floods, inundations, mudflows and landslips. The continued heavy rain for weeks ravages many regions of Ecuador, Peru and Bolivia.

It is important to note that the development of the active El-Niño, existent as the first variant, is observed more often in the beginning and the middle of the southern summer. The second and especially the third variants are observed mainly during the end of the southern summer.

An important feature in the zonal circulation during the active El-Niño period is the existence of a stable and extensive equatorial westerly wind zone at an altitude of $500 \mathrm{hPa}$. The westerly wind velocities reach $10-15 \mathrm{~m} / \mathrm{s}$ above the central parts of the tropical Pacific. Also it is evident that the tropical cyclones, appearing during the warm ENSO phase, are not weak and single tropical depressions, but rather vertically well-developed baroclinic circulation structures.

The distribution of the divergent wind velocity potential in the active class is characterized by the appearance of negative values in the lower troposphere and of positive values in the upper troposphere above the region from New Guinea to $120 \mathrm{~W}$. Such a combination of the divergent wind velocity potential fields above the studied region during the active westerly winds leads to the development of the intensive ascending motions, causing, firstly, the strong cloud formation in an unusual region and, secondly, a great amount of additional heat in the atmosphere as a result of water vapor condensation.

It should be noted that the formation of cyclonic centers in the tropical atmosphere found on the resulting wind maps, are well confirmed by the analysis of the photos of cloudiness from the Japanese geostationary satellite. It is shown that the isolated cloud formations with the vortical structure correspond to each cyclonic vortex. These clouds are in strong contrast to the almost cloudless weather during the trade wind regime (the normal class).

To investigate the interaction between the tropical Pacific and atmosphere under El-Niño (1997-1998) - La-Niña (1999-2000) conditions, the SVD method is used. It is important to note that SVD method for the investigation of interaction between SST and atmospheric circulation allows to separate two different processes in the system ocean-

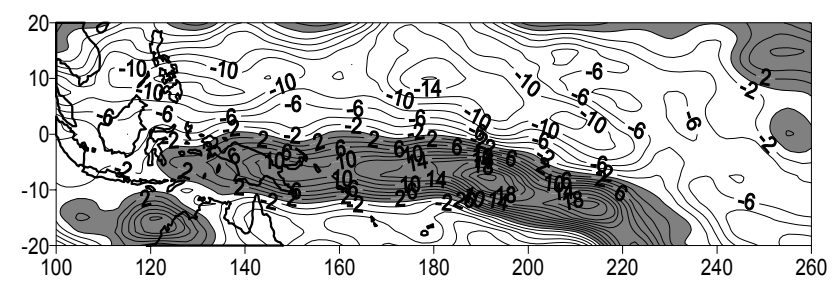

Fig. 2a. The zonal component of the wind velocity (m/s), 31 January 1998 (the first variant of the localization of equatorial westerly winds above the tropical Pacific during the active class), H850.

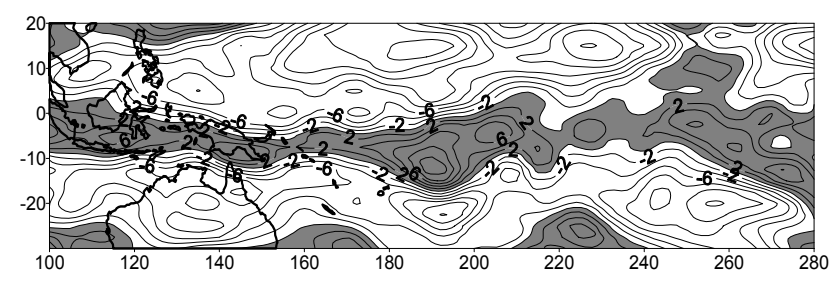

Fig. 2b. The zonal component of the wind velocity $(\mathrm{m} / \mathrm{s}), 20$ February 1998 (the second variant of the localization of equatorial westerly winds above the tropical Pacific during the active class), H850.

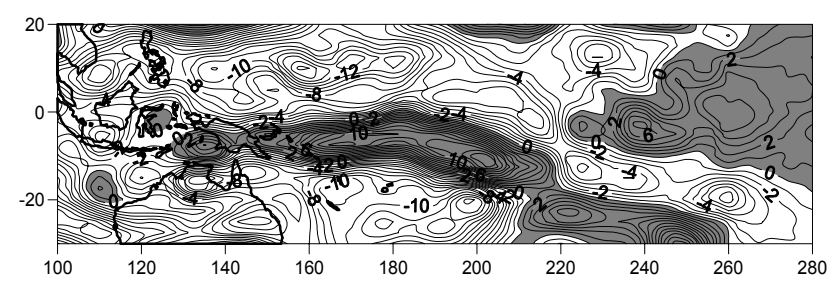

Fig. 2c. The zonal component of the wind velocity $(\mathrm{m} / \mathrm{s}), 04$ February 1998 (the third variant of the localization of equatorial westerly winds above the tropical Pacific during the active class), H850.

atmosphere - mean climate conditions and anomaly. The SST anomaly and zonal wind velocity anomaly on $850 \mathrm{hPa}$ isobaric surface are chosen as the characteristics of ocean and atmosphere. The SVD is done for the 5 points (the averaged data over the ten-grid squares), which describes most adequately the circulation fields in the equatorial Pacific (Fig. 1).

It is found that in SVD the first two vectors are the most significant for these characteristics. The first vector reflects the main circulative peculiarities of synoptic nature above the tropical Pacific (Fig. 3a). The ENSO-like structure may be found in the second SVD vector distribution (Fig. 3b).

In order to estimate the correlation between SST anomaly and zonal wind velocity anomaly the lag-cross correlation function for the temporal coefficients of the first and second SVD vectors are calculated.

The maximum coefficient of correlation (54\%) of the first SVD vector between the tropical Pacific SST anomaly and the zonal wind velocity anomaly is observed when the processes in atmosphere lag the SST for 10 days (Fig. 4a). This corresponds to the normal conditions in tropics - when SST positive anomalies contribute to the enhancement of deep convection and intensified cloud formation. 


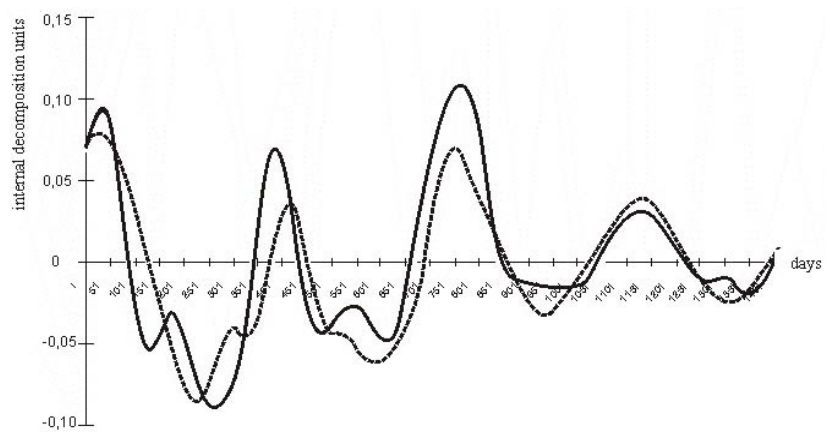

Fig. 3a. Temporal coefficients of the first SVD vector between the tropical Pacific SST anomaly (solid line) and the zonal wind velocity anomaly (dotted line); the correlation between SST anomaly and zonal wind velocity anomaly is $49.8 \%$ (ENSO: Jan 1997-Dec 2000).

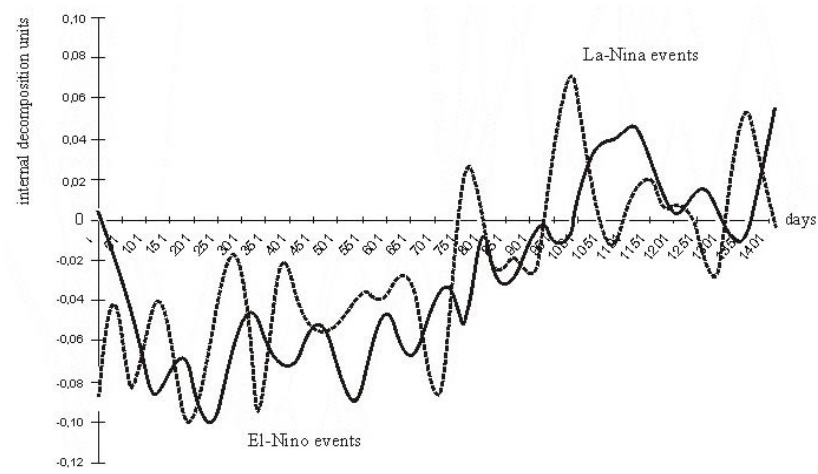

Fig. 3b. Temporal coefficients of the second SVD vector between the tropical Pacific SST anomaly (solid line) and the zonal wind velocity anomaly (dotted line); the correlation between SST anomaly and zonal wind velocity anomaly is $33.2 \%$ (ENSO: Jan 1997-Dec 2000).

The maximum correlation between temporal coefficients of the second SVD vector between the tropical Pacific SST anomaly and the zonal wind velocity anomaly is found at lag 190 days (58\%) and 110 days (62\%) (Fig. 4b). In these cases the processes in the ocean happen later, i.e. atmosphere gives the first signal (when the southern trade winds weaken) 6 months before and the second, more powerful signal (when the tropical cyclogenesis activates), 4 months before the beginning of the SST anomaly development.

\section{Conclusion}

1. During the ENSO 1997-1998 culmination phase (three summer months of the Southern Hemisphere) the activity of equatorial westerly winds changes from 8 to 12 times, i.e. average every $8-10$ days there is a change in the regime of atmospheric circulation. In $21 \%$ of all cases the equatorial westerly wind zone above the tropical Pacific is very weak or does not exist at all (the break class).

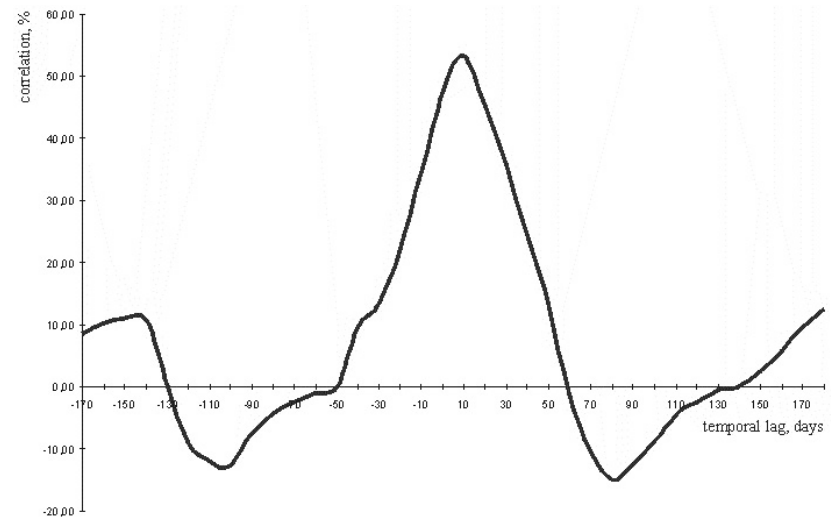

Fig. 4a. Lag-cross correlation function for the temporal coefficients of the first SVD vector; $\tau$-temporal lag; $\tau<0$ : the SST anomalies lag wind anomalies; $\tau>0$ : the SST anomalies lead wind anomalies (ENSO 1997-2000).

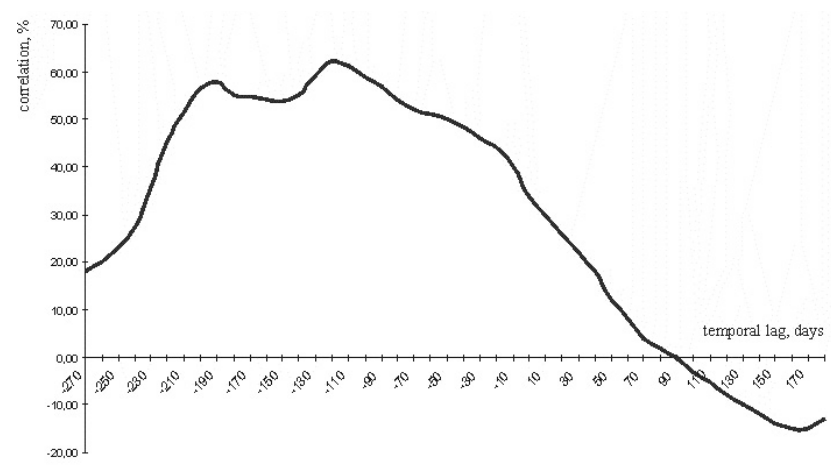

Fig. 4b. Lag-cross correlation function for the temporal coefficients of the second SVD vector; $\tau$-temporal lag; $\tau<0$ : the SST anomalies lag wind anomalies; $\tau>0$ : the SST anomalies lead wind anomalies (ENSO 1997-2000).

2. All synoptical situations within the active class during the ENSO 1997-1998 culmination phase are subdivided into three more typical variants of the location of equatorial westerly winds above the tropical Pacific. The development of the active El-Niño, existent as the first variant, is observed more often in the beginning and the middle of the southern summer. The second and especially the third variants are observed mainly during the end of the southern summer.

3. The westerly wind anomaly above the tropical Pacific strongly depends on the conditions of tropical cyclogenesis, which is characterized by large variability. Thus there are days when 8-9 tropical cyclones of different intensity exist simultaneously above the tropical Pacific (the active class) and in some days of the ENSO culmination phase cyclonic vortices are not observed at all and the anticyclonic circulation is ill-defined (the break class). 
4. An important feature in the zonal circulation during the active El-Niño period is the existence of a stable and extensive equatorial westerly wind zone at an altitude of $500 \mathrm{hPa}$. The westerly wind velocities reach $10-15 \mathrm{~m} / \mathrm{s}$ above the central parts of the tropical Pacific. It is evident that the tropical cyclones, appearing during the warm ENSO phase, are not weak and single tropical depressions, but rather vertically well-developed baroclinic circulation structures.

5. The distribution of the divergent wind velocity potential in the active class leads to the development of the intensive ascending motions, causing, firstly, the strong cloud formation in an unusual region and, secondly, a great amount of additional heat in the atmosphere as a result of water vapor condensation.

6. Using the SVD method the connection between the atmospheric circulation and SST of equatorial Pacific is investigated. It is shown that atmosphere gives the first signal (when the southern trade winds weaken) 6 months before and the second, more powerful signal (when the tropical cyclogenesis activates), 4 months before the beginning of the SST anomaly development.
Edited by: P. Fabian and J. L. Santos

Reviewed by: two anonymous referees

\section{References}

Harrison, D. E. and Vecchi, G. A.: Westerly wind events in the tropical Pacific, 1986-95, J. Cli., 10, 3131-3156, 1997.

Hartten, L. M.: Synoptic settings of westerly wind bursts, J. Geophys. Res., 101 (D12), 16 997-17 019, 1996.

Petrosyants, M. A., Semenov, E. K., and Sokolikhina, E. V.: Atmospheric circulation in periods of different intensity of equatorial westerly winds during the 1982-83 El-Niño - Southern Oscillation culmination / Meteorology and Hydrology, 11, 5-15, 1998.

Semenov, E. K. and Kornyushin, O. G.: The atlas of the circulation characteristics in troposphere and lower stratosphere of the tropical zone, Moscow, Hydrometeo Publ., 104 p., 1988. 